\title{
Churg-Strauss syndrome: a case report ${ }^{*}$
}

\author{
Sindrome de Churg-Strauss: relato de caso
}

\section{Gabriel Lacerda Fernandes ${ }^{1}$, Arivaldo Araújo Teixeira ${ }^{2}$, Ana Graziela Santana Antón ${ }^{3}$, Alan Timóteo Rodrigues Reis $^{1}$, Ana Carolina Rezende de Freitas ${ }^{4}$, Dunya Bachour Basílio ${ }^{5}$}

Fernandes GL, Teixeira AA, Antón AGS, Reis ATR, Freitas ACR, Basílio DB. Churg-Strauss syndrome: a case report. Radiol Bras. 2014 JulAgo;47(4): $259-261$.

Abstract Churg-Strauss syndrome is a rare systemic disease primarily characterized by hypereosinophilia, asthma and vasculitis. The lung is the organ most frequently involved. In the present report, the authors describe a relatively rare finding in this disease - the presence of a pulmonary nodule -, while recalling the main radiological findings and the most relevant differential diagnoses.

Keywords: Vasculitis; Eosinophilia; Asthma.

Re su mo A síndrome de Churg-Strauss é uma doença sistêmica rara caracterizada principalmente por hipereosinofilia, asma e vasculite. 0 pulmão é o órgão mais frequentemente envolvido. Neste relato, descrevemos uma alteração relativamente rara nesta doença - a presença de um nódulo pulmonar -, ao mesmo tempo que recordamos os principais achados obtidos em exames radiológicos e os seus diagnósticos diferenciais mais importantes.

Unitermos: Vasculite; Eosinofilia; Asma.

\section{INTRODUCTION}

Churg-Strauss syndrome was first described in 1951 by Churg and Strauss ${ }^{(1)}$. It is characterized by a triad of clinical signs: asthma, hypereosinophilia and necrotizing vasculitis. Usually the patients' age range is between 20 and 40 years, and both men and women are equally affected ${ }^{(1-7)}$. The etiology of Churg-Strauss syndrome is still unknown, but it has been attributed to hypersensitivity to an inhaled agent. Rarely a parasitic infection or antigenic drug for desensitization represents a triggering event ${ }^{(1)}$. Asthma is the main characteristic of this syndrome ${ }^{(1-7)}$. Lungs are the organs most frequently involved, followed by kidneys. Pulmonary hemorrhage and glomerulonephritis are much less common than in other small vessels vasculitis ${ }^{(1-5,7)}$

The diagnosis of Churg-Strauss syndrome is achieved if four or more of the following clinical signs are present: a) asthma; b) more than $10 \%$ eosinophilia in blood count; c) mono or polyneuropathy attributable to systemic vasculitis;

* Study developed at Hospital de Base do Distrito Federal (HBDF), Brasília, DF, Brazil.

1. MDs, Residents of Radiology and Imaging Diagnosis, Hospital de Base do Distrito Federal (HBDF), Brasília, DF, Brazil.

2. MD, Radiologist, Diagnóstico das Américas (DASA/Exame-Pasteur), Brasília, DF, Brazil.

3. MD, Radiologist, Hospital Brasília and Diagnóstico das Américas (DASA/ExamePasteur), Brasília, DF, Brazil.

4. MD, Radiologist, Hospital de Base do Distrito Federal (HBDF) and Instituto do Coração de Brasília, Brasília, DF, Brazil.

5. MD, Pathologist, Hospital de Base do Distrito Federal (HBDF), Brasília, DF, Brazil.

Mailing Address: Dr. Gabriel Lacerda Fernandes. SQSW 306, Bloco B, ap. 509, Edifício Ouro Preto, Setor Sudoeste. Brasília, DF, Brazil, 70673-432. E-mail: lacerdagabriel@hotmail.com.

Received June 8, 2013. Accepted after revision October 22, 2013. d) migratory or transient pulmonary opacities; e) paranasal sinuses abnormalities; f) extravascular eosinophils at biopsy. At histopathological analysis, necrotizing small vessel vasculitis and an eosinophil-rich inflammatory infiltrate with necrotizing granulomas are observed ${ }^{(1,4,5)}$

The most common radiographic pulmonary manifestations of Churg-Strauss syndrome consist of bilateral and transient non-segmental areas of consolidation, without any predilection for any pulmonary region, resembling Loeffler's syndrome, or may be predominantly peripheral $50 \%$ of cases), resembling chronic eosinophilic pneumonia or organizing pneumonia ${ }^{(1-5,7)}$. At high-resolution computed tomography, the most common findings include subpleural ground glass opacities or consolidations with lobular distribution, centrilobular nodules, bronchial wall thickening, and interlobular septal thickening. Less common findings include hyperinsufflation, hilar or mediastinal lymph node enlargement, pleural or pericardiac effusion, and also small or large nodular opacities which rarely cavitate ${ }^{(1-5)}$.

\section{CASE REPORT}

A male, 38-year-old patient, joiner, reporting rhinorrhea, sneezes and nasal mucosal lesion, after he initiated his professional activity four months ago. The patient sought medical assistance and underwent antibiotic therapy, presenting improvement of his condition; but the symptoms resumed after re-exposure to work environment. The patient coursed with enlargement of parotid regions, cervical adenopathy, dysfagia, weight loss (about $11 \mathrm{~kg}$ in six months) and productive cough with purulent expectoration with blood traces. Blood count revealed 24\% eosinophilia. Neck magnetic resonance imaging demonstrated enlarged palatine tonsils and 
major salivary glands, besides bilateral maxillo-ethmoidal sinusopathy. Chest computed tomography (Figures 1 and 2) demonstrated the presence of multiple pulmonary nodules, consolidation and ground glass opacities, raising the diagnostic hypotheses of Wegener granulomatosis and ChurgStrauss syndrome. Transthoracic biopsy of a nodule in the left lower lobe demonstrated intense eosinophilic infiltrate and small vessels vasculitis compatible with Churg-Strauss syndrome (Figures 3 and 4).

\section{DISCUSSION}

The present report describes a case of Churg-Strauss syndrome that is the less common and most poorly characterized pulmonary vasculitis in terms of pathological descriptions and imaging findings, and that presented a unusual

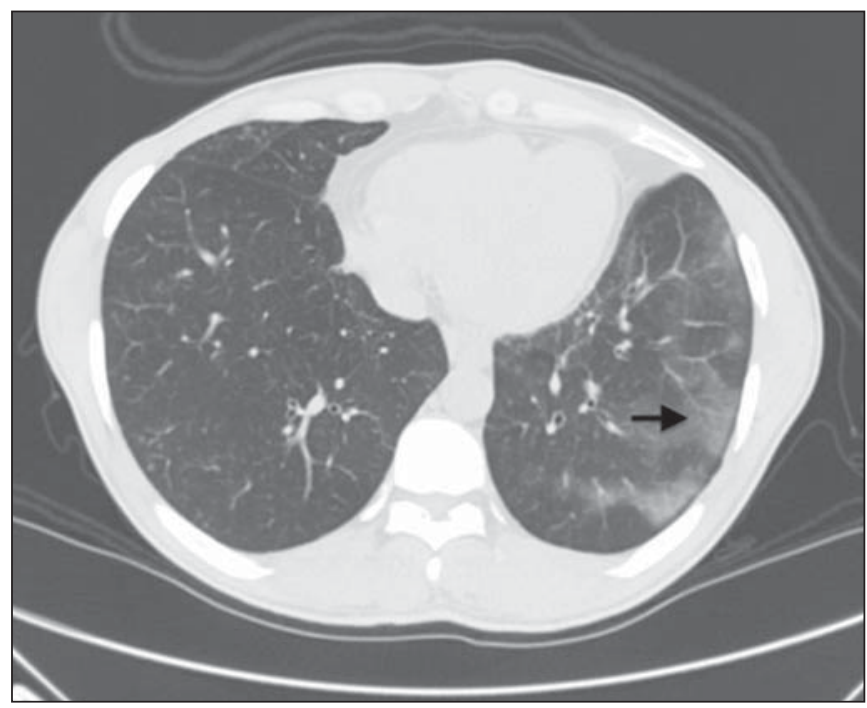

Figure 1. Chest computed tomography. Axial image demonstrates diffuse areas of ground glass opacities with predominance in the left lung (arrow).

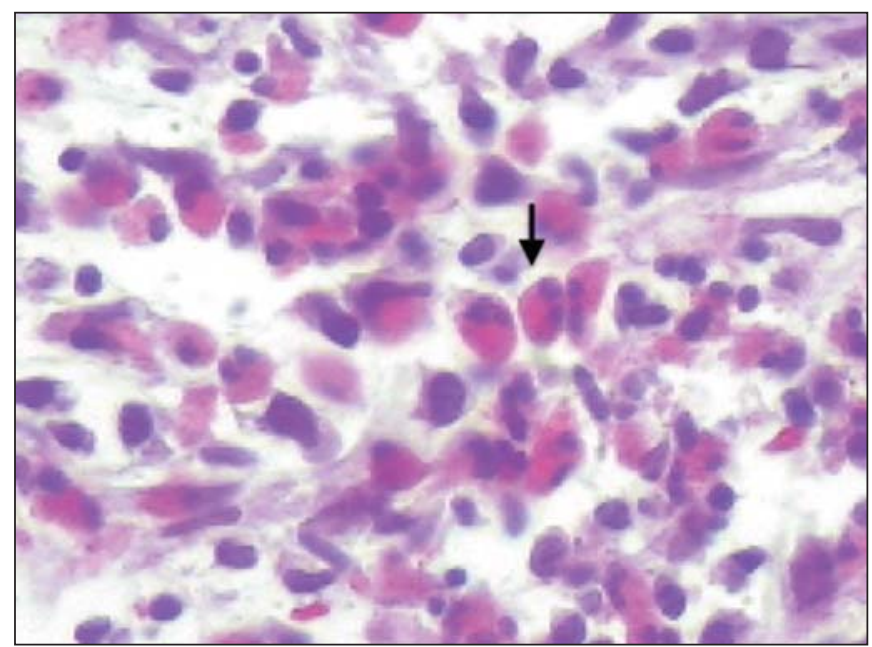

Figure 3. Histopathological hematoxylin-eosin section and $400 \times$ magnification demonstrate intense eosinophilic infiltrate (arrow). manifestation - a centimetric peripheral pulmonary nodule, a finding that is observed in less than $10 \%$ of $\operatorname{cases}^{(1,2,4,6)}$.

One may suspect of Churg-Strauss syndrome as a pattern of ground glass opacities and consolidations is seen in a patient with history of asthma and eosinophilia. Such a syndrome presents a spectrum of histological manifestations in the lungs, including asthmatic bronchitis, eosinophilic pneumonia, extravascular granulomas and necrotizing vasculitis ${ }^{(1,2,4,7)}$.

Radiological differential diagnoses include disorders associated with prominent eosinophilic infiltrate or a combination of granulomatous with eosinophilic inflammation $^{(1,5,7)}$. Chronic eosinophilic pneumonia is probably the most relevant lesion to be distinguished in Churg-Strauss syndrome. It frequently occurs in asthmatic patients, and eosinophilia may be present, although not so high as in

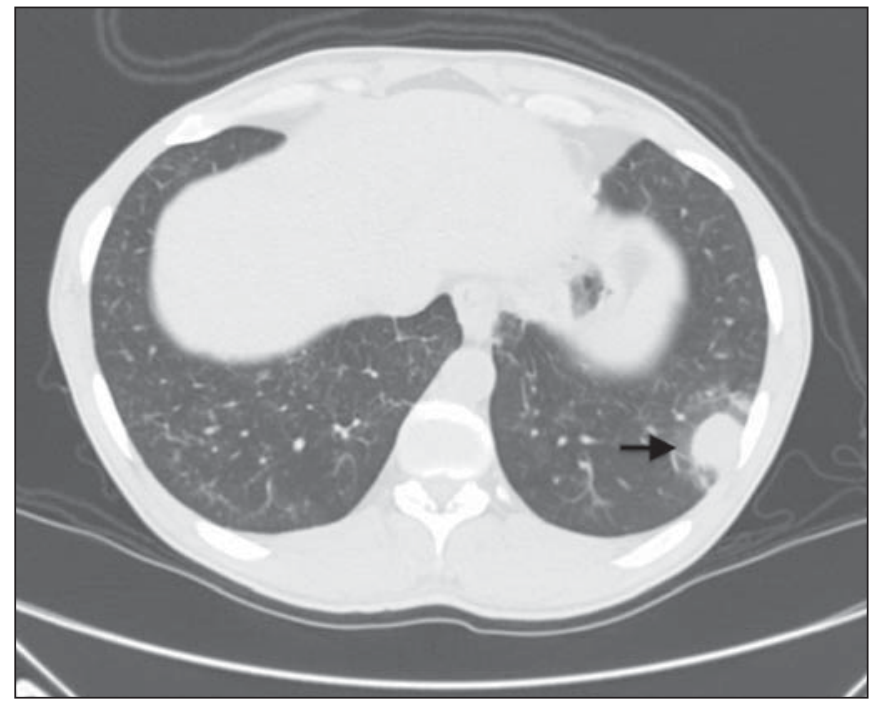

Figure 2. Chest computed tomography. Axial image demonstrates the presence of a pulmonary nodule in the left lower lobe, with irregular contour and a ground glass halo that may represent a hemorrhagic component (arrow).

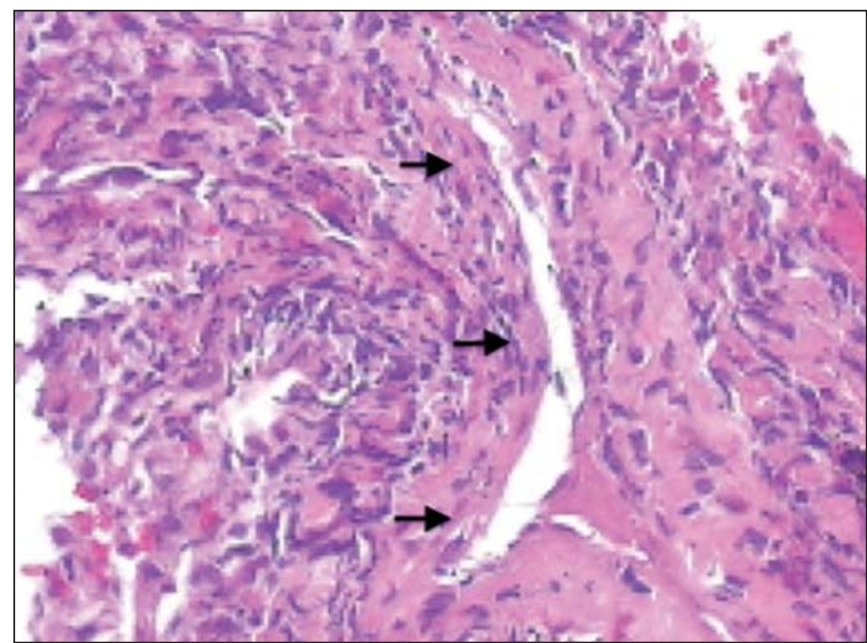

Figure 4. Histopathological hemotoxylin-eosin section and $200 \times$ magnification demonstrates small vessel vasculitis. Thick walled, small caliber vessel permeated by inflammatory infiltrate intermingled with polymorphonuclear cells and eosinophils (arrows) 
Churg-Strauss syndrome. At chest computed tomography, chronic eosinophilic pneumonia is characterized by peripheral, homogeneous air space consolidation, while in ChurgStrauss syndrome, the consolidation tends to present a lobular distribution, with frequent presence of centrilobular nodules and ground glass opacities ${ }^{(7)}$. Multiple or solitary, excavated nodules represent the most common findings in Wegener's granulomatosis ${ }^{(1,2,4-7)}$. Other conditions include hypereosinophilic syndrome, allergic bronchopulmonary aspergillosis and infections such as coccidioidomycosis ${ }^{(3,5,7)}$.

\section{REFERENCES}

1. Frazier AA, Rosado-de-Christenson ML, Galvin JR, et al. Pulmonary angiitis and granulomatosis: radiologic-pathologic correlation. Radiographics. 1998;18:687-710.
2. Mayberry JP, Primack SL, Müller NL. Thoracic manifestations of systemic autoimune diseases: radiographic and high-resolution CT findings. Radiographics. 2000;20:1623-35.

3. Johkoh T, Müller NL, Akira M, et al. Eosinophilic lung diseases: diagnostic accuracy of thin-section in 111 patients. Radiology. 2000; 216:773-80.

4. Castañer E, Alguersuari A, Gallardo X, et al. When to suspect pulmonary vasculitis: radiologic and clinical clues. Radiographics. 2010; $30: 33-53$.

5. Chung MP, Yi CA, Lee HY, et al. Imaging of pulmonary vasculitis. Radiology. 2010;255:322-41.

6. Hansell DM. Small-vessel diseases of the lung: CT-pathologic correlates. Radiology. 2002;225:639-53.

7. Katzenstein ALA. Diagnostic features and differential diagnosis of Churg-Strauss syndrome in the lung. A review. Am J Clin Pathol. 2000;114:767-72. 